\title{
Phytochemical Screening and Antibacterial Activity of Citrus Sinensis Peel Extracts on Clinical Isolates of Staphylococcus Aureus and Salmonella Typhi
}

\author{
${ }^{*}$ Ali M${ }^{1}$, Diso $\mathrm{SU}^{2}$, Nas FS 3 and Nasir $\mathrm{AS}^{4}$ \\ ${ }^{1}$ Department of Biological Sciences, Federal University Gusau \\ ${ }^{2}$ Department of Pharmaceutical Technology, School of Technology, Kano State Polytechnics \\ ${ }^{3}$ Department of Biological Sciences, Bayero University Kano \\ ${ }^{4}$ Department of Medical Laboratory Science, Bayero University Kano \\ *Corresponding author: Muhammad Ali, Department of Biological Sciences, Federal University Gusau, Nigeria, \\ E-mail: alimuhd4real@gmail.com
}

Received: 25 August, 2018; Accepted: 10 October, 2018; Published: 25 October, 2018

\begin{abstract}
The study was conducted to determine the phytochemical composition, antibacterial activity and activity index orange (Citrus sinensis (L) Osbeck) peel extracts against clinical isolates of Staphylococcus aureus and Salmonella typhi. The result of phytochemical screening of the peel extracts showed the presence of alkaloid, glycoside, saponin, tannin, flavonoid, terpenoid and phenol. The result of the antibacterial efficacy of the extracts against the isolates indicated the extracts were active against the isolates with higher activity in ethanol extract (with average zone of inhibition of $15 \mathrm{~mm}$ ) when compared to aqueous extract $(12.25 \mathrm{~mm})$. The result of susceptibility of the isolates to the extracts showed Staphylococcus aureus was more sensitive to the extract with average zone of inhibition of $15.25 \mathrm{~mm}$ when compared to Salmonella typhi with average zone of inhibition of $12.00 \mathrm{~mm}$. The minimum inhibitory concentration (MIC) of the extracts showed that dilutions of various concentrations of aqueous and ethanol of peel extracts can inhibit the growth or kill the isolates at a concentration of between $2.125-20 \mathrm{mg} /$ $\mathrm{ml}$. the average activity index of the extracts on the test isolates was found to be 0.64 which indicated that the plant extract can compete with the standard antibiotic used. Statistical analysis of the results indicated that there is no significant different in the activity of the extracts against the isolates used at $p<0.05$. Findings from this study support the use of orange peel extracts for medicinal purposes.
\end{abstract}

\section{Keywords}

Antibacterial activity, Citrus sinensis, Phytochemical, Salmonella typhi, Staphylococcus aureus.

\section{Introduction}

Natural products such as plant have been an integral part of ancient (Such as Chinese, Ayurvedic and Egyptian) traditional medicine systems [1]. Medicinal plant is any plant in which in one or more of its organs (stem, root, leaves, rhizomes, fruits, flower and seeds), contains substances that can be used for therapeutic purposes, or which are precursors for chemo-pharmaceutical semi synthesis [2]. Such a plant (medicinal plant) will have such parts employed in the treatment or control of a disease condition and therefore contains biochemical components called phytochemicals that are of medical importance [3]. Phytochemicals are considered as bioactive substances of plant origin. They are regarded as secondary metabolites because they are of little need by the plant that manufactured them. The phytochemicals are naturally synthesized in all parts of plant such as bark, leaves stem, root, flower, fruits, seeds, etc [4]. Most of the drugs enlisted as orthodox medication were originally obtained from plant [5]. Many studies today confirmed that the herbs boost the immune system by stimulating the production of disease fighting white blood cells [6].

Sweet orange (Citrus sinensis (L.) Osbeck) is a small evergreen tree $7.5 \mathrm{~m}$ high and sometimes up to $15 \mathrm{~m}$. Its origin is China and it has been cultivated over the years, but is grown commercially worldwide in tropics, semitropical and some warm temperate regions and has become the most widely planted tree fruit 
Citation: Ali M, Diso SU, Nas (2018) Phytochemical Screening and Antibacterial Activity of Citrus sinensis Peel Extracts on Clinical Isolates of Staphylococcus aureus and Salmonella typhi. J Allied Pharm Sci: 50-54. DOI: https://doi.org/10.29199/JAPS.101014.

in the world today according to Nicolosi et al. [7]. Citrus fruit products act as antimicrobial agents against the bacteria and fungus. The sweet orange product has an important and physiological role because of its commercial value in pharmaceutical and food industries of the entire world [8]. The antioxidant activity is also present in the plant materials due to the presence of many active phytochemicals such as flavonoids, vitamins, cumarins, terpenoids, carotenoids, saponin, lignin and plant sterols and so on [8]. The sweet orange fruits and their juices are an important source of bioactive methanol, the compound is important to human nutrition which include the antioxidant such as ascorbic acid, phenolic compound, flavonoids and pectins [9]. The present study was conducted to determine the phytochemical constituents, antibacterial activity and activity of aqueous and ethanol extracts of sweet orange peel on clinical isolates of Staphylococcus aureus and Salmonella typhi isolated from stool samples of typhoid fever patients attending Murtala Muhammad General Hospital Kano, Nigeria.

\section{Collection, identification and Authenti- cation of Orange Fruits}

The plant used in this study (Citrus sinensis (L.) Osbeck) were obtained from fruit sellers at Dorayi quarters, Opposite Sarkin Dutse Estate, Gwale Local Government Area in Kano state, Nigeria. After collection, the Orange fruits were identified and authenticated at the herbarium in the Department of Plants Science, Bayero University Kano with the following voucher number BUKHAN 0389, voucher specimens were deposited in the herbarium for future references. The fruits were washed, peeled and air dried at room temperature for 14 days. The dried orange peels were ground into fine powder using sterile pestle and mortar under laboratory condition and stored in container for further use.

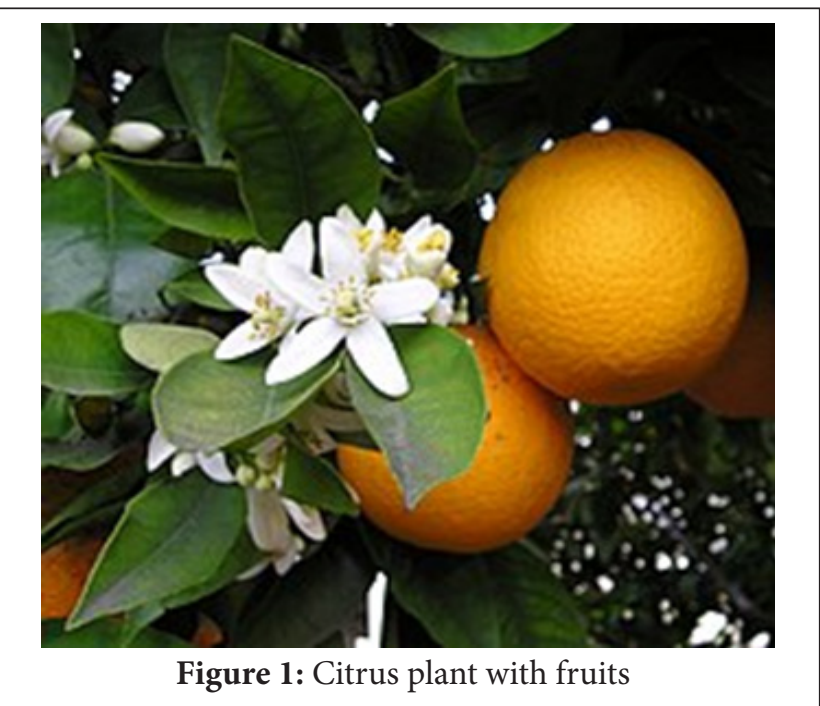

\section{Bacteria isolates}

Clinical isolates of Salmonella typhi and Staphylococcus aureus, were used in this study. The isolate was obtained from Microbi- ology laboratory of Murtala Muhammad General Hospital Kano, Nigeria. The bacteria were isolated from typhoid fever infected patient attending the Hospital. The isolates were diagnosed in the Hospital to the species level by using different laboratory procedures including; Gram's stain, cultural characterization and $\mathrm{Bi}$ ochemical tests include (Indole, Methyl red, Vogues Proskeaur, Catalase, Citrate utilization) for Salmonella typhi while catalase, coagulase and DNAse test for Staphylococcus aureus. The isolates were maintained on Nutrient agar slants at 40C and transported to Laboratory of Science Laboratory Technology Department, School of Technology Kano for further use.

\section{Extraction of Orange Peel}

Aqueous and $80 \%$ ethanol solvents were used for extraction process of the phytochemical components of the orange peel. For aqueous extract, water extraction method as described by Ahmed and Beg [10] was employed. During the process, $100 \mathrm{~g}$ of the ground peel was weighted and mixed with $500 \mathrm{ml}$ of distilled water in a sterile conical flask and kept for 4 days with intermittent shaking. The extract was filtered using Whatman filter paper and the filtrate was concentrated in water bath at $50^{\circ} \mathrm{C}$. For ethanol, $100 \mathrm{~g}$ of the powdered peel was extracted in $500 \mathrm{ml}$ of ethanol for 3 days. The mixture was filtered using Whatman No. 1 filter paper and the extract was evaporated to dryness using rotary evaporator at $40^{\circ} \mathrm{C}$. The residue obtained was diluted using $10 \%$ Dimethylsulphoxide (DMSO) to produce $100 \mathrm{mg} / \mathrm{ml}$ of the extract from which various concentrations of 75, 50 and $25 \mathrm{mg} /$ $\mathrm{ml}$ were produced.

\section{Phytochemical Screening of the Extracts}

Phytochemical screening was conducted using laboratory method as described by Soforowa [11]. This was done to determine the presence of alkaloid, saponin, steroid, glycoside, tannin, terpenoid, anthraquinone, flavonoid and reducing sugar in the aqueous and ethanol extracts of the orange peel.

\section{Antibacterial Activity of the Extracts}

Agar well diffusion method was adapted to determine the antibacterial activity of the orange peel extracts against the test isolates in this study. During the process, $0.1 \mathrm{ml}$ of standardize organisms (0.5 MacFarland standard) were introduced onto the surface of Mueller Hinton agar in a sterile Petri dish and labelled accordingly. A sterile cork borer $5 \mathrm{~mm}$ was used to produce five wells at equal distance in the inoculated agar. The wells were filled with different concentrations of the extracts accordingly as $25,50,75$ and $100 \mathrm{mg} / \mathrm{l}$ while the last well contain $50 \mathrm{mg} / \mathrm{ml}$ of standard antibiotic Gentamicin (Micro lab limited) which was used as positive control in the study. The agar plates were allowed to diffuse for a period of hour and incubated at $37^{\circ} \mathrm{C}$ for 24 hours. After then, the diameter of the zones of inhibition around each well was measured to the nearest millimetres [12].

\section{Determination of Minimum Inhibitory Concentra- tion (MIC) of the Extracts}


Citation: Ali M, Diso SU, Nas (2018) Phytochemical Screening and Antibacterial Activity of Citrus sinensis Peel Extracts on Clinical Isolates of Staphylococcus aureus and Salmonella typhi. J Allied Pharm Sci: 50-54.

The MIC of the extracts was determined using broth dilution technique. Two fold serial dilutions of the extracts were prepared by adding $2 \mathrm{ml}$ of $100 \mathrm{mg} / \mathrm{ml}$ of the extract into a test tube containing $2 \mathrm{ml}$ of Nutrient broth, thus producing solution containing $50 \mathrm{mg} / \mathrm{ml}$ of the extract. The process continued serially up to test tube No. 5, hence producing the following concentrations; $50,25,12.5,6.253 .125 \mathrm{mg} / \mathrm{ml}$. Test tube No. 6 do not contain extracts and serve as negative control. Exactly $0.5 \mathrm{ml}$ of $0.5 \mathrm{Mc}$ Farland equivalent standards of test organisms were introduced into the test tubes and incubated at $370 \mathrm{C}$ for 24 hours. After incubation the test tubes were observed for growth by checking for turbidity [13].

\section{Determination of Minimum Bactericidal Concen- tration (MBC) of the Extracts}

From the result of MIC, the test tubes that did not show visible growth were used for MBC determination. About $0.1 \mathrm{ml}$ was aseptically transferred onto the surface of Mueller Hinton agar plates. The plates were incubated at $37^{\circ} \mathrm{C}$ for 24 hours. The MBC of the extracts was recorded as the lowest concentration of the extract that had less than 99\% growth on Mueller Hinton agar plates [13].

\section{Evaluation of activity index of the extracts}

The activity index (AI) of the crude extracts was calculated as described by Vedpriya et al. [14]. The Activity index (AI) is expressed as follows;

Activity index $(\mathrm{AI})=\frac{\text { Mean zone of inhibition of the extracts }(\mathrm{mm})}{\text { Zone of inhibition obtained from standard drug }(\mathrm{mm})}$

\section{Statistical Analysis}

The data of average zone of inhibition produced by the isolates against the antibiotics used was analyzed using one way Analysis of Variance (ANOVA) with the aid of statistical program SPSS (Statistical package for Social Sciences) version 21.0. Significance level for the differences was set at $\mathrm{p}<0.05$.

\section{Results}

\section{Phytochemical Screening}

Phytochemical screening of Citrus sinensis peel extracts in (Table 1) indicates the presence of alkaloid, tannin, saponin, glycoside, flavonoid, terpenoid, and Phenols while reducing sugar, steroid and anthraquinone were absent.

\section{Antibacterial Activity of the Extracts}

The antibacterial activity of aqueous and ethanolic extract of Citrus sinensis peel against Clinical isolates of Salmonella typhi and Staphylococcus aureus is presented in (Table 2). The result showed that the ethanol extract demonstrated higher activity of $19 \mathrm{~mm}$ at $100 \mathrm{mg} / \mathrm{ml}$. The zone of inhibition shown by the control (50 $\mathrm{mg} / \mathrm{ml} \mathrm{Gentamicin)} \mathrm{is} \mathrm{found} \mathrm{to} \mathrm{be} 24 \mathrm{~mm}$

\begin{tabular}{llll}
\hline S/N & Phytochemical & Aqueous extract Ethanol extract \\
\hline 1 & Alkaloids & + & + \\
2 & Flavonoid & + & + \\
3 & Glycosides & + & + \\
4 & Reducing sugar & - & - \\
5 & Saponin & + & + \\
6 & Steroids & - & - \\
7 & Phenols & + & + \\
8 & Terpenoid & + & + \\
9 & Anthraquinone & - & + \\
10 & Tannin & + & \\
\hline
\end{tabular}

Key: + = presence of phytochemical, - = absent of phytochemical

Table 1: Phytochemical constituents of the extracts

Organisms/zone of inhibition $(\mathrm{mm})$

Extracts Conc. $(\mathrm{mg} / \mathrm{ml})$ Salmonella typhi S. aureus

\begin{tabular}{llll}
\hline & 25 & 07 & 10 \\
PAE & 50 & 08 & 12 \\
& 75 & 13 & 15 \\
& 100 & 17 & 16 \\
& 25 & 10 & 12 \\
PEE & 50 & 14 & 17 \\
& 75 & 18 & 20 \\
& 100 & 19 & 20 \\
& 50 & 21 & 22 \\
\hline
\end{tabular}

Key: PAE = Peel Aqueous Extract, PEE = Peel Ethanolic Extract.

Table 2: Antibacterial Activity of the Citrus sinensis Peel Extract against the isolate

\section{MIC and MBC of the Extracts}

The minimum inhibitory Concentration of aqueous and ethanol extract of orange peel is represented in Table 3. The result showed dilutions of various concentrations of aqueous and ethanol extracts can inhibit and/or kill the isolates. Lower MIC $(3.125 \mathrm{mg} / \mathrm{ml})$ was shown by ethanol extract than aqueous extract with $6.25 \mathrm{mg} / \mathrm{ml}$. MBC of the extract ranges between $12.50-50 \mathrm{mg} / \mathrm{ml}$. 
Citation: Ali M, Diso SU, Nas (2018) Phytochemical Screening and Antibacterial Activity of Citrus sinensis Peel Extracts on Clinical Isolates of Staphylococcus aureus and Salmonella typhi. J Allied Pharm Sci: 50-54. DOI: https://doi.org/10.29199/JAPS.101014.

\begin{tabular}{|l|c|c|c|c|}
\hline \multicolumn{4}{|c|}{ Aqueous peel extracts } & Ethanol peel extract \\
\hline Isolates & MIC (mg/ml) & MBC ( $\mathbf{m g} / \mathbf{m l})$ & MIC (mg/ml) & MBC (mg/ml) \\
\hline Salmonella typhi & 6.25 & 12.5 & 6.25 & 25 \\
\hline Staphylococcus aureus & 12.5 & 50 & 6.25 & 25 \\
\hline
\end{tabular}

\section{Activity index of the peel extracts}

The activity index of the Orange (Citrus sinensis) peel extracts against standard antibiotic is presented in Table 4 . The result showed that leaves ethanol extract has the highest activity index of 0.70 while the lowest activity is shown by leaves aqueous extract $(0.57)$. The average activity index of the extracts is found to be 0.64 .

\begin{tabular}{lccc}
\hline Extracts & Total ZOI & Average ZOI & Activity index \\
\hline PAE & 98 & 12.25 & 0.57 \\
PEE & 120 & 15.00 & 0.70 \\
Total & 218 & 13.63 & 0.64 \\
\hline
\end{tabular}

Key: PAE $=$ Peel Aqueous Extract, PEE $=$ Peel Ethanolic Extract, $\mathrm{ZOI}=$ zone of inhibition.

Table 4: Activity index of the extracts against standard antibiotic used

\section{Discussion}

The Phytochemical screening of the Citrus sinensis (Orange) peel extracts indicated the presence of alkaloid, tannin, saponin, glycoside, flavonoid, terpenoid, and phenols. The presence of the above phytochemicals in the plant parts was responsible for its antibacterial activity. Flavonoids have been shown to possess anti-inflammatory, anti-hepatotoxic and antimicrobial activities [15]. Saponins are known to possess antibacterial activities $[16,17]$ whilst tannins play an important role in wound healing and also possess some antimicrobial activities. According to this study, Alkaloid is present in the extracts. Alkaloid consists of large group of nitrogenous compound which are widely used as anticancer anesthetics and Central Nervous Stimulants. Alkaloids are known to play some metabolic roles and control development in living system. It also interferes with cell division, hence the presence of alkaloids in the Citrus sinensis (Orange) peel could account for their use as antimicrobial agents.

The antibacterial activity of the plant showed that the plant peel extracts demonstrated an antimicrobial effect against the test isolate with higher activity in ethanol extract compared to aqueous extract. The ethanolic peel extract had highest zone of inhibition of $20 \mathrm{~mm}$ at $100 \mathrm{mg} / \mathrm{ml}$ against S. aureus while 19 $\mathrm{mm}$ for $S$. typhi, while aqueous extract had highest zone of inhibition of $17 \mathrm{~mm}$ at the same concentration for S. typhi while
$16 \mathrm{~mm}$ against $S$. aureus at $100 \mathrm{mg} / \mathrm{ml}$. This may be due to the better solubility of the active components in the organic solvent (ethanol) than water which leads to better efficacy of the ethanol extracts. It suggests that the active component is more soluble in ethanol than in the other solvents. However, Doughari et al. [18] stated that the anti-microbial effect of the plant could be due to the bioactive compounds such as the Phytochemicals constituent present in the plant. The results showed that the potency of the orange peel extracts on the test isolates had different hierarchy of susceptibility among the organisms. The findings of this study indicated that Gram positive bacteria ( $S$. aureus) was more sensitive to the extracts with average zone of inhibition of $15.25 \mathrm{~mm}$ when compared to Gram negative ( $S$. typhi) with average zone of inhibition of $12.00 \mathrm{~mm}$. This could be attributed to presence of phospholipid layer in the Gram negative bacteria. Generally, against the isolated bacteria, higher concentration of the extract shows a greater zone of inhibition; this results is in agreement with the report of Bisno and Stevens [19] which states that the higher the concentration of antibacterial substance, the higher it shows an appreciable zone of inhibition. The antibacterial activity of aqueous extracts of peel, juice and leaves from fresh Citrus sinensis was evaluated against three Gram positive (Staphylococcus aureus, Streptococcus pyogenes and Enterococcus faecalis) and six Gram negative bacteria (Pseudomonas aeruginosa, Klebsiella pneumoneae, Escherichia coli, Staphylococcus typhi, Proteus spp. and Moraxella catarrhalis). Citrus juices showed the highest activity against most of the studied bacteria isolates. According to the study, moderate activity was produced by Citrus peel and the lowest activity was produced by Citrus leaves extracts [20]. Minimum inhibitory concentration of aqueous and ethanol extract of orange peel showed dilutions of various concentrations of aqueous and ethanol of peel extracts can inhibit and/or kill the isolates. Lower MIC $(3.125 \mathrm{mg} / \mathrm{ml})$ was shown by ethanol extract than aqueous extract with $6.25 \mathrm{mg} / \mathrm{ml}$. The $\mathrm{MBC}$ of the extracts ranged from $12.50-50.00 \mathrm{mg} / \mathrm{ml}$

The activity index of the Citrus sinensis peel extracts against standard antibiotic is presented in Table 4 . The result showed that leaves ethanol extract has the highest activity index of 0.70 while the lowest activity is shown by leaves aqueous extract (0.57). The average activity index of the extracts is found to be 0.64 which indicated that the extract can compete to the standard antibiotic used. Statistical analysis of the result revealed that the table value ( $\mathrm{p}$ value at $\mathrm{p}<0.05$ ) is greater than the calculated value for analysis of variance between the extracts; therefore, there is no significant different in the activity of the two extracts against the isolates used, hence null hypothesis is accepted. 
Citation: Ali M, Diso SU, Nas (2018) Phytochemical Screening and Antibacterial Activity of Citrus sinensis Peel Extracts on Clinical Isolates of Staphylococcus aureus and Salmonella typhi. J Allied Pharm Sci: 50-54.

\section{Conclusion}

Phytochemical screening of the seeds extracts indicated the presence of presence of alkaloid, tannin, saponin, flavonoid and phenols, terpenoid, glycoside. The antibacterial activity of the peel extracts against Salmonella typhi and Staphylococcus aureus showed that the peel leaves extracts demonstrated an antimicrobial effect against the isolates. The Minimum inhibitory Concentration (MIC) of aqueous and ethanol extract of orange peel showed dilutions of various concentrations of aqueous and ethanol of peel extracts can inhibit and/or kill the isolates. The average activity index of the extracts is found to be 0.64 which indicated that the extract can compete to the standard antibiotic used. Findings from this work support the use of extracts from Orange peel for medicinal purpose.

\section{Acknowledgement}

The authors wish to acknowledge to the staff of Microbiology Laboratory of Murtala Muhammad Specialist Hospital for provision of Samples. Thanks to the Management of School of Technology, Kano State Polytechnics for the use of laboratory facilities.

\section{References}

1. Sarker S, Nahar L (2007) Chemistry for pharmacy students: general, organic and natural product chemistry. John Wiley and Sons pp 283-359.

2. World Health Organization (WHO). Use of antibacterials outside human medicine and result and antibacterial resistance in humans. World Health Organization 2002. Archieved from the Original on 13 May, 2004

3. Doughari JH (2012) Phytochemicals: extraction methods, basic structures and mode of action as potential chemotherapeutic agents. In Phytochemicals-A global perspective of their role in nutrition and health. InTech Open.

4. Das K, Tiwari RKS, Shrivastava DK (2010) Techniques for evaluation of medicinal plant products as antimicrobial agents: current methods and future trends. J Medicinal Plants Res 4: 104-111

5. Leslie WR, Ellen RP, Banting DW, Fillery ED (2005) Longitudinal microbiological investigation of a hospitalized population of older adults with a high root surface caries risk. Journal of Dental Research, 64: 1377-1381
6. Odebiyi OO, Sofowora EA (1978) Phytochemical screening of Nigerian medicinal plants II. Lloydia, 41: 234-246

7. Nicolosi E, Deng ZN, Gentile A, La Malfa S, Continella G, et al. (2000) Citrus phylogeny and genetic origin of important species as investigated by molecular markers. Theor Appl Genet, 100: 11551166.

8. Mathur A, Verma SK, Purohit R, Gupta V, Dua VK, et al. (2011) Evaluation of in vitro antimicrobial and antioxidant activities of peel and pulp of some citrus fruits. J Biotechnol Biotherapeutics 1: 1-17.

9. Hegazy AE, Ibrahium MI (2012) Antioxidant activities of orange peel extracts. World Appl Sci J 18: 684-688

10. Ahmad I, Beg AZ (2001) Antimicrobial and phytochemical studies on 45 Indian medicinal plants against multi-drug resistant human pathogens. J Ethnopharmacology 74:113-123

11. Sofowora A (1993). Medicinal plants and traditional medicine in Africa. Spectrum books Itd. 2nd Edn pp. 26-100

12. Ali M, Aminu F, Ibrahim IS (2017) In-Vitro Assessment of Antibacterial Activity and Phytochemical Screening of Vitex Doniana on Clinical Isolate of Salmonella Typhi. IN-VITRO 3: 1

13. Ali M, Yahaya A, Zage AU, Yusuf ZM (2017) In-vitro Antibacterial Activity and Phytochemical Screening of Psidium guajava on Some Enteric Bacterial Isolates of Public Health Importance. J Advances Med Pharmac Sci 12: 1-7

14. Vedpraya AY, Sanjay K, Sandeep, Yadar JP (2010) Antimicrobial activity of Cassia occidentalis against various human pathogenic microbes. Life Sci Med Res 9: 1-10.

15. Madubunyi II (1995) Antimicrobial activities of the constituents of Garcinia kola seeds. Int J Pharmacognosy 33: 232-237

16. González-Lamothe R, Mitchell G, Gattuso M, Diarra MS, Malouin F, Bouarab K (2009) Plant antimicrobial agents and their effects on plant and human pathogens. Int J Mol Sci 10: 3400-3419

17. Cowan MM (1999) Plant products as antimicrobial agents. Clin Microbial Rev 22: 564-582.

18. Doughari JH, Elmahmood AM, Manzara S (2007) Studies on the antibacterial activity of root extracts of Carica papaya L. African J Microbiol Res 1: 37-41.

19. Bisno AL, Stevens DL (1996) Streptococcal infections of skin and soft tissues. N Engl J Med 334: 240-246.

20. Hindi NKK, Chabuck ZAG, Hindi SKK (2014) Antibacterial evaluation of aqueous extracts of four Citrus species in Hilla, Iraq. Int J Pharmacolog Screening Methods 4: 45-6. 